\title{
Impact of Ipsilateral Blood Draws, Injections, Blood Pressure Measurements, and Air Travel on the Risk of Lymphedema for Patients Treated for Breast Cancer
}

Chantal M. Ferguson, Meyha N. Swaroop, Nora Horick, Melissa N. Skolny, Cynthia L. Miller, Lauren S. Jammallo, Cheryl Brunelle, Jean A. O'Toole, Laura Salama, Michelle C. Specht, and Alphonse G. Taghian

See accompanying article on page 655

All authors: Massachusetts General Hospital, Harvard Medical School, Boston, MA.

Published online ahead of print at www.jco.org on December 7, 2015.

Supported by Award No. R01CA139118 (A.G.T.) and Award No. P50CA089393 (A.G.T.) from the National Cancer Institute and the Adele McKinnon Research Fund for Breast Cancer-Related Lymphedema.

Terms in blue are defined in the glossary, found at the end of this article and online at www.jco.org

Presented at the San Antonio Breast Cancer Symposium, San Antonio, TX, December 9-12, 2014.

The content is solely the responsibility of the authors and does not necessarily represent the official views of the National Cancer Institute or the National Institutes of Health.

Authors' disclosures of potential conflicts of interest are found in the article online at www.jco.org. Author contributions are

found at the end of this article.

Corresponding author: Alphonse G. Taghian, MD, PhD, Department of Radiation Oncology, Massachusetts General Hospital, 100 Blossom St, Boston, MA 02114; e-mail: ataghian@ partners.org.

() 2015 by American Society of Clinical Oncology

0732-183X/16/3407w-691w/\$20.00 DOI: 10.1200/JCO.2015.61.5948

\section{$\begin{array}{llllllll}\text { A } & \text { B } & \text { S } & \text { T } & \text { R } & \text { A } & \text { C } & \text { T }\end{array}$}

\section{Purpose}

The goal of this study was to investigate the association between blood draws, injections, blood pressure readings, trauma, cellulitis in the at-risk arm, and air travel and increases in arm volume in a cohort of patients treated for breast cancer and screened for lymphedema.

\section{Patients and Methods}

Between 2005 and 2014, patients undergoing treatment of breast cancer at our institution were screened prospectively for lymphedema. Bilateral arm volume measurements were performed preoperatively and postoperatively using a Perometer. At each measurement, patients reported the number of blood draws, injections, blood pressure measurements, trauma to the at-risk arm(s), and number of flights taken since their last measurement. Arm volume was quantified using the relative volume change and weight-adjusted change formulas. Linear random effects models were used to assess the association between relative arm volume (as a continuous variable) and nontreatment risk factors, as well as clinical characteristics.

\section{Results}

In 3,041 measurements, there was no significant association between relative volume change or weight-adjusted change increase and undergoing one or more blood draws $(P=.62)$, injections $(P=.77)$, number of flights (one or two $[P=.77]$ and three or more $[P=.91] v$ none), or duration of flights ( 1 to 12 hours $[P=.43$ ] and 12 hours or more $[P=.54] v$ none). By multivariate analysis, factors significantly associated with increases in arm volume included body mass index $\geq 25(P=.0236)$, axillary lymph node dissection $(P<.001)$, regional lymph node irradiation $(P=.0364)$, and cellulitis $(P<.001)$.

\section{Conclusion}

This study suggests that although cellulitis increases risk of lymphedema, ipsilateral blood draws, injections, blood pressure readings, and air travel may not be associated with arm volume increases. The results may help to educate clinicians and patients on posttreatment risk, prevention, and management of lymphedema.

\section{J Clin Oncol 34:691-698. (c) 2015 by American Society of Clinical Oncology}

\section{INTRODUCTION}

Clinicians and national guidelines strongly advise patients with breast cancer to avoid blood draws, injections, blood pressure readings, and trauma to the at-risk arm during and after treatment to reduce the risk of developing cellulitis and breast cancer-related lymphedema (BCRL). ${ }^{1-6}$ Patients are also advised to exercise caution when flying by wearing prophylactic compression sleeves. ${ }^{1,3,5}$ These guidelines are based on anecdotal information, and comprehensive data demonstrating the efficacy of such precautionary behaviors do not exist, highlighted in a recent statement by the National Lymphedema Network. ${ }^{5}$ The guidelines place a large amount of burden on patients and clinicians, who go to great lengths to exercise precautionary behaviors and face high levels of anxiety when they accidentally do not abide by the guidelines. Therefore, we sought to investigate the association between blood draws, injections, blood pressure readings, trauma, and cellulitis in the at-risk arm and flying on increases in arm volume in a large prospective cohort of patients undergoing treatment of breast cancer. 
Lymphedema is a potential adverse effect of breast cancer treatment characterized by arm swelling, discomfort, and impaired upper extremity function in its later stages. The development of lymphedema is the result of a compromised lymphatic drainage system after the removal of lymph nodes or radiation to the axillary lymph nodes. Patients with breast cancer carry a lifelong risk of developing lymphedema; the average time to onset is 14.4 months after treatment completion. ${ }^{7,8}$ Consequently, if patients comply with cautionary guidelines, they must exercise risk-reducing practices for the rest of their lives.

Well-defined risk factors for developing lymphedema include axillary lymph node dissection (ALND), ${ }^{9-15}$ regional lymph node irradiation (RLNR), ${ }^{8,16-19}$ higher body mass index (BMI), and older age at diagnosis. ${ }^{7,8,11,14,20-30}$ It remains unclear why, among patients with similar demographic and treatment-related characteristics, some go on to develop lymphedema. This variation has prompted speculation that events including blood draws, injections, blood pressure readings, trauma to the arm, air travel, and cellulitis might incite lymphedema. ${ }^{6,31}$ Despite the prevalence and persistence of recommendations to pursue precautionary behavior after breast cancer treatment, few data exist to support these practices, and investigation into the topic is warranted. ${ }^{5}$

\section{PATIENTS AND METHODS}

\section{Study Design}

Patients with newly diagnosed breast cancer between 2009 and 2014 who were prospectively screened for lymphedema at our institution were included in this analysis. Bilateral arm volume measurements were obtained using an optoelectric Perometer (Pero-system, Wuppertal, Germany), which uses infrared light to measure limb circumference and calculate arm volume. All patients had a preoperative baseline measurement, a postoperative measurement, a measurement after chemotherapy and/or radio therapy, and measurements at regular follow-up intervals corresponding with oncology visits. ${ }^{32-35}$ Regular follow-up intervals correspond to time periods of between 3 and 7 months. Occasionally patients are measured more frequently at their request. The protocol for lymphedema screening has been previously published and approved by the institutional review board ${ }^{33}$ (ClinicalTrials. gov identification number NCT01521741).

Arm volume changes were quantified using the relative volume change $(\mathrm{RVC})^{33}$ formula after unilateral breast surgery or the weight-adjusted volume change (WAC) formula after bilateral breast surgery. ${ }^{34}$ The RVC equation accounts for preoperative differences in arm volume by using a baseline measurement and for nontreatment-related changes, including weight gain or loss, by comparing the surgical arm to the nonsurgical arm. ${ }^{33,34}$ Briefly, RVC $=$ $\{[A(2) U(1) / U(2) A(1)\}-1)$, where $A(1)$ and $A(2)$ are arm volumes on the surgical or ipsilateral side at preoperative and postoperative measurements, and $U(1)$ and $U(2)$ are arm volumes on the contralateral side at corresponding time points. ${ }^{33}$ The WAC calculates changes in arm volume compared with a preoperative arm measurement for each arm independently and accounts for weight changes that could influence arm size. ${ }^{34}$ RVC and WAC have been shown to classify lymphedema similarly. ${ }^{34}$ Lymphedema was defined as RVC or WAC $\geq 10 \%{ }^{7,15,36}$

At each Perometer measurement, patients were asked to complete a survey on which they reported the number of blood draws, injections, blood pressure readings, and trauma to the at-risk arm(s); number of flights and the length of the flight since their last measurement; and use of compression sleeve while flying. Self-reported trauma ranged from bruising to arm fractures.

This analysis includes information from each patient visit at which both an arm volume measurement and a survey were obtained.

\section{Patient Population}

All 632 patients included in this study had a new diagnosis of invasive breast cancer at their baseline measurement, more than 6 months of postsurgical follow-up, and at least one follow-up arm measurement. Patient and clinocopathologic characteristics were collected via medical record review. Patients who undergo sentinel lymph node biopsy are still at risk for developing lymphedema and are often advised to exercise risk reduction practices just like those who undergo ALND. Therefore, both groups were included in the study. Episodes of cellulitis were defined as clinical signs of infection in the ipsilateral arm and/or breast that required antibiotics. Each side was evaluated independently for patients who underwent bilateral breast surgery, resulting in a total of 760 at-risk arms available for analysis. In our hospital, the majority of patients who chose to undergo contralateral prophylactic mastectomy undergo sentinel lymph node biopsy on their unaffected breast to stage an occult breast cancer if discovered on final pathology. Therefore, the unaffected breasts for patients undergoing bilateral mastectomies were included in the analysis because they are also at risk for developing lymphedema. Patients were censored from the analysis after a diagnosis of distant metastases and recurrence and if they wore a compression sleeve while flying.

\section{Statistical Analysis}

The Kaplan-Meier method was used to estimate the 2-year cumulative incidence of lymphedema, defined by RVC/WAC $\geq 10 \%$. Linear random effects models were used to assess the association between relative arm volume (as a continuous variable), clinical risk factors, and episodes of nonprecautionary behavior. These models account for the correlation between arm volume measurements obtained from the same patient and, for patients who underwent bilateral breast surgery, on the same side of the body. At each measurement, the number of blood draws, injections, blood pressure readings, trauma, and episodes of cellulitis were analyzed both as continuous variables and as dichotomous variables, categorized according to whether patients reported having had one or more events versus none. Number of and hours spent on flights in total since last follow-up were analyzed as both continuous and trichotomous variables. Model estimates give the mean change in RVC or WAC associated with a one-unit increase in a continuous risk factor and the mean difference in RVC or WAC between subgroups for categorical variables. Univariate model results were used to estimate and plot the mean RVC or WAC within each subgroup for categorical clinical and nontreatment-related variables, along with the $95 \% \mathrm{CI}$ for the mean and the $P$ value associated with the comparison of means. The multivariate model was chosen by starting with a model that included all variables that were significant at the .10 significance level in the univariate analysis, as well as all nonprecautionary behaviors, and removing one variable at a time until only significant $(P<.05)$ variables remained. Because cellulitis is in the causal pathway between the risk events and arm volume increase, it was not included in the model selection process to avoid overadjustment bias.

Cox proportional hazards models were used to assess the association between risk of cellulitis and risk events. Patients who developed cellulitis in the postoperative period were excluded from this analysis because of lack of information on risk events. In addition, in analyzing the association between risk events and subsequent cellulitis, we evaluated the relationship between the risk of infection and the number of risk events reported before the cellulitis episode.

\section{RESULTS}

\section{Patient Population}

Six hundred thirty-two patients with a total of 3,041 postoperative measurements were included. Median age at diagnosis was 52 years (range, 28 to 81 years), and median BMI was $26 \mathrm{lb} / \mathrm{in}^{2}$ (range, 16 to $59 \mathrm{lb} / \mathrm{in}^{2}$; Table 1 ); $92.1 \%$ of the cohort was white, $0.6 \%$ Hispanic, 2\% African American, 2.7\% Asian, and 2.6\% unknown. Patients were followed for a median of 24 months (6 to 60 months) 


\begin{tabular}{|c|c|c|c|}
\hline & \multicolumn{2}{|c|}{ Lymphedema } & \multirow[b]{2}{*}{ Overall $(\mathrm{N}=760)$} \\
\hline & No $(n=697)$ & Yes $(n=63)$ & \\
\hline Age at diagnosis, years* & 52 & 51 & 52 \\
\hline $\mathrm{BMI}, \mathrm{Ib} / \mathrm{in}^{2 *}$ & 25.4 & 29.1 & 25.6 \\
\hline Follow-up, months* & 23.59 & 34.31 & 24.03 \\
\hline No. of postoperative visits* & 4 & 5 & 4 \\
\hline Months between visits* & 7.14 & 6.45 & 7.09 \\
\hline \multicolumn{4}{|l|}{ Tumor type } \\
\hline \multicolumn{4}{|l|}{ None } \\
\hline No. & 112 & 13 & 125 \\
\hline$\%$ & 16.1 & 20.6 & 16.4 \\
\hline \multicolumn{4}{|l|}{ Invasive } \\
\hline No. & 583 & 50 & 633 \\
\hline$\%$ & 83.6 & 79.4 & 83.3 \\
\hline \multicolumn{4}{|l|}{ Not available } \\
\hline No. & 2 & 0 & 2 \\
\hline$\%$ & 0.3 & 0 & 0.3 \\
\hline \multicolumn{4}{|l|}{ Laterality } \\
\hline \multicolumn{4}{|l|}{ Unilateral } \\
\hline No. & 473 & 31 & 504 \\
\hline$\%$ & 67.9 & 49.2 & 66.3 \\
\hline \multicolumn{4}{|l|}{ Bilateral } \\
\hline No. & 224 & 32 & 256 \\
\hline$\%$ & 32.1 & 50.8 & 33.7 \\
\hline \multicolumn{4}{|l|}{ Breast surgery } \\
\hline \multicolumn{4}{|l|}{ Lumpectomy } \\
\hline No. & 359 & 18 & 377 \\
\hline$\%$ & 51.5 & 28.6 & 49.6 \\
\hline \multicolumn{4}{|l|}{ Mastectomy } \\
\hline No. & 338 & 45 & 383 \\
\hline$\%$ & 48.5 & 71.4 & 50.4 \\
\hline \multicolumn{4}{|l|}{ Axillary surgery } \\
\hline \multicolumn{4}{|l|}{ None } \\
\hline No. & 53 & 7 & 60 \\
\hline$\%$ & 7.6 & 11.1 & 7.9 \\
\hline SLNB & & & \\
\hline No. & 519 & 22 & 541 \\
\hline$\%$ & 74.5 & 34.9 & 71.2 \\
\hline ALND & & & \\
\hline No. & 125 & 34 & 159 \\
\hline$\%$ & 17.9 & 54 & 20.9 \\
\hline Neoadjuvant chemotherapy & & & \\
\hline No & & & \\
\hline No. & 606 & 50 & 656 \\
\hline$\%$ & 86.9 & 79.4 & 86.3 \\
\hline Yes & & & \\
\hline No. & 91 & 13 & 104 \\
\hline$\%$ & 13.1 & 20.6 & 13.7 \\
\hline Adjuvant chemotherapy & & & \\
\hline No & & & \\
\hline No. & 416 & 25 & 441 \\
\hline$\%$ & 59.7 & 39.7 & 58 \\
\hline Yes & & & \\
\hline No. & 281 & 38 & 319 \\
\hline$\%$ & 40.3 & 60.3 & 42 \\
\hline Hormonal therapy & & & \\
\hline No & & & \\
\hline No. & 121 & 12 & 133 \\
\hline$\%$ & 17.4 & 19 & 17.5 \\
\hline Yes & & & \\
\hline No. & 576 & 51 & 627 \\
\hline$\%$ & 82.6 & 81 & 82.5 \\
\hline Radiation therapy & & & \\
\hline None & & & \\
\hline No. & 248 & 17 & 265 \\
\hline$\%$ & 35.6 & 27 & 34.9 \\
\hline & ontinued in ne & t column) & \\
\hline
\end{tabular}

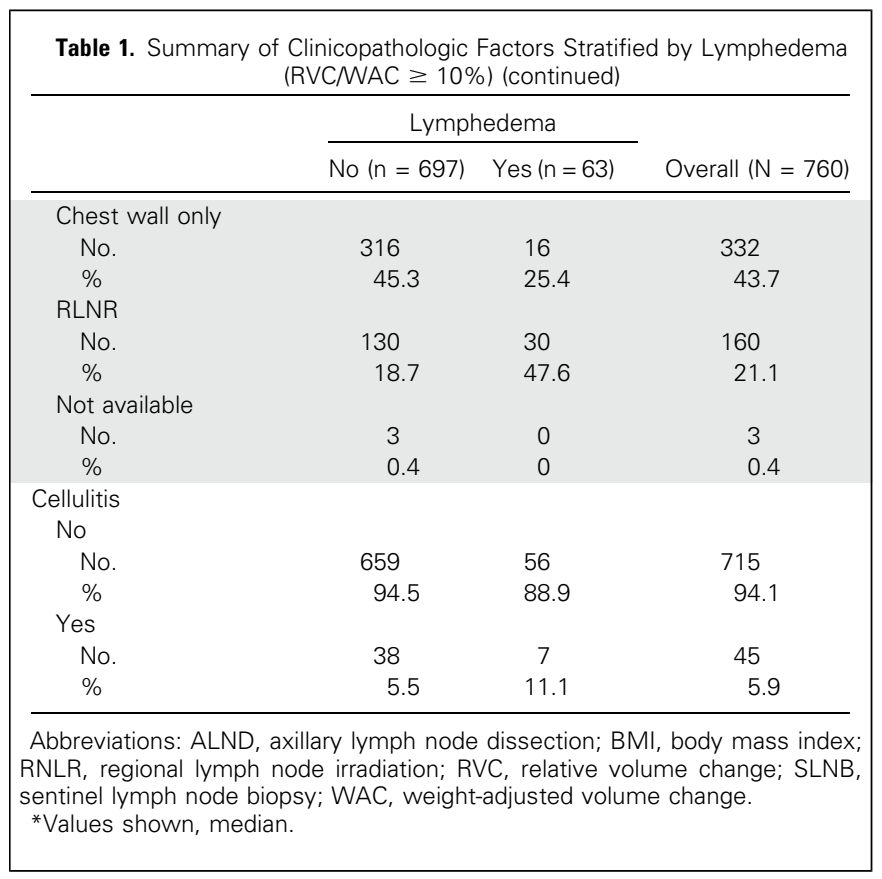

and had a median of four postoperative visits (one to 16). The median time between measurements was 7 months (interquartile range, 6.2 months). Thirteen percent of patients had one measurement, $34 \%$ had two to three measurements, $40 \%$ had four to six measurements, and $13 \%$ had seven to 16 measurements. By medical record review, 5.9\% (45 of 760) of treated breasts had at least one episode of cellulitis any time after surgery requiring antibiotics (Table 1); 47\% (21 of 45) of cellulitis episodes occurred in the immediate postoperative period and therefore before the first postoperative arm measurement. At 24 months, the cumulative incidence of BCRL as defined by an RVC or WAC $\geq 10 \%$ was $7.72 \%$ (95\% CI, $5.82 \%$ to $10.22 \%$ ).

\section{Nonprecautionary Behaviors}

In $8.5 \%$ (251 of 2,965) of responses, patients reported having one or more blood draw in their affected $\operatorname{arm}(\mathrm{s})$ since their last measurement, $2.1 \%$ (63 of 2,961) of responses reported having one or more injection, $16.3 \%$ (482 of 2,961) of responses reported having one or more blood pressure measurements taken, and 1.0\% (37 of 2,999) of responses reported trauma to the at-risk arm (Table 2$)$. Thirty percent $(878$ of 2,960$)$ of patients had flown since their last measurement (Table 2).

\section{Univariate and Multivariate Analyses}

By univariate analysis, there was no significant association between an increased RVC or WAC and undergoing one or more blood draws $(P=.62)$, injections $(P=.77)$, trauma to the at-risk $\operatorname{arm}(P=.08)$, number of flights (one or two $[P=.77]$ and three or more $[P=.91] v$ none), or duration of flights ( 1 to 12 hours $[P=$ $.43]$ and 12 hours or more $[P=.54] v$ none) (Fig 1 ). Having a $\mathrm{BMI} \geq 25 \mathrm{lb} / \mathrm{in}^{2}$ at time of diagnosis $(P=.0064)$, undergoing ALND $(P=.0003)$, having blood pressure readings $(P=.034)$, RLNR $(P<.001)$, and cellulitis $(P<.001)$ were significantly associated with arm volume increases (Table 3; Fig 1). When 


\begin{tabular}{|c|c|c|c|}
\hline \multirow[b]{3}{*}{ Risk Factor } & \multicolumn{3}{|c|}{ No. of Measurements With Event } \\
\hline & \multicolumn{2}{|c|}{ Lymphedema } & \multirow[b]{2}{*}{ Overall $(\mathrm{N}=3,041)$} \\
\hline & No $(n=192)$ & Yes $(n=2,849)$ & \\
\hline \multicolumn{4}{|l|}{ Blood draws } \\
\hline \multicolumn{4}{|l|}{ None } \\
\hline No. & 2,538 & 176 & 2,714 \\
\hline$\%$ & 89.1 & 91.7 & 89.2 \\
\hline \multicolumn{4}{|l|}{$1+$} \\
\hline No. & 241 & 10 & 251 \\
\hline$\%$ & 8.5 & 5.2 & 8.3 \\
\hline \multicolumn{4}{|l|}{ Not available } \\
\hline No. & 70 & 6 & 76 \\
\hline$\%$ & 2.5 & 3.1 & 2.5 \\
\hline \multicolumn{4}{|l|}{ Injections } \\
\hline \multicolumn{4}{|l|}{ None } \\
\hline No. & 2,726 & 183 & 2,909 \\
\hline$\%$ & 95.7 & 95.3 & 95.7 \\
\hline \multicolumn{4}{|l|}{$1+$} \\
\hline No. & 60 & 3 & 63 \\
\hline$\%$ & 2.1 & 1.6 & 2.1 \\
\hline \multicolumn{4}{|l|}{ Not available } \\
\hline No. & 63 & 6 & 69 \\
\hline$\%$ & 2.2 & 3.1 & 2.3 \\
\hline \multicolumn{4}{|l|}{ Blood pressure } \\
\hline None & & & \\
\hline No. & 2,305 & 174 & 2,479 \\
\hline$\%$ & 80.9 & 90.6 & 81.5 \\
\hline $1+$ & & & \\
\hline No. & 470 & 12 & 482 \\
\hline$\%$ & 16.5 & 6.3 & 15.9 \\
\hline Not available & & & \\
\hline No. & 74 & 6 & 80 \\
\hline$\%$ & 2.6 & 3.1 & 2.6 \\
\hline Trauma & & & \\
\hline No & & & \\
\hline No. & 2,780 & 182 & 2,962 \\
\hline$\%$ & 97.6 & 94.8 & 97.4 \\
\hline Yes & & & \\
\hline No. & 29 & 8 & 37 \\
\hline$\%$ & 1 & 4.2 & 1.2 \\
\hline Not available & & & \\
\hline No. & 40 & 2 & 42 \\
\hline$\%$ & 1.4 & 1 & 1.4 \\
\hline Flights, No. & & & \\
\hline None & & & \\
\hline No. & 1,949 & 133 & 2,082 \\
\hline$\%$ & 68.4 & 69.3 & 68.5 \\
\hline $1-2$ & & & \\
\hline No. & 453 & 28 & 481 \\
\hline$\%$ & 15.9 & 14.6 & 15.8 \\
\hline $3+$ & & & \\
\hline No. & 389 & 8 & 397 \\
\hline$\%$ & 13.7 & 4.2 & 13.1 \\
\hline Not available & & & \\
\hline No. & 58 & 23 & 81 \\
\hline$\%$ & 2 & 12 & 2.7 \\
\hline Flights, hours & & & \\
\hline None & & & \\
\hline No. & 1,946 & 132 & 2,078 \\
\hline$\%$ & 68.3 & 68.8 & 68.3 \\
\hline $1-12$ & & & \\
\hline No. & 429 & 23 & 452 \\
\hline$\%$ & 15.1 & 12 & 14.9 \\
\hline $12+$ & & & \\
\hline No. & 408 & 13 & 421 \\
\hline$\%$ & 14.3 & 6.8 & 13.8 \\
\hline Not available & & & \\
\hline No. & 66 & 24 & 90 \\
\hline$\%$ & 2.3 & 12.5 & 3 \\
\hline
\end{tabular}

analyzed as continuous variables, age at diagnosis $(P=.25)$, the number of ipsilateral blood draws $(P=.92)$, injections $(P=.85)$, blood pressure readings $(P=.15)$, and number $(P=.34)$ or duration of flights $(P=.98)$ were not associated with an increase in RVC or WAC by univariate analysis. In a subset of patients who underwent ALND, BMI $\geq 25 \mathrm{lb} / \mathrm{in}^{2}(P=.0051)$ and cellulitis $(P<.001)$ remained significant, but blood draws $(P=.26)$, injections $(P=.35)$, blood pressures $(P=.39)$, trauma $(P=.23)$, and air travel (one or two $[P=.96]$ and three or more $[P=.88] v$ no flights) or duration of flights ( 1 to 12 hours $[P=.85]$ and 12 hours or more $[P=.69] v$ none) were not associated with increased arm swelling.

By multivariate analysis, factors significantly associated with increases in arm volume included $\mathrm{BMI} \geq 25 \mathrm{lb} / \mathrm{in}^{2}(P=.0236)$, $\operatorname{ALND}(P<.001), \operatorname{RLNR}(P=.0364)$, and cellulitis $(P<.001)($ Fig 2$)$. None of the nonprecautionary behaviors were significantly associated with arm volume change in the multivariate analysis.

Further investigation of the association between risk events and subsequent cellulitis revealed that blood draws (hazard ratio [HR], 0.977; $P=.91$ ), injections (HR, 1.101; $P=.5$ ), and blood pressure readings (HR, $0.943 ; P=.1$ ) on the ipsilateral arm were not significantly associated with cellulitis.

\section{DISCUSSION}

A large, prospective cohort of patients with breast cancer was analyzed to investigate the association of nonprecautionary behaviors and the subsequent risk of lymphedema. No significant association was found between undergoing ipsilateral blood draws, injections, and blood pressure readings, and trauma to the at-risk arm, air travel, and arm swelling. Increase in arm swelling was associated with ALND, RLNR, BMI $\geq 25 \mathrm{lb} / \mathrm{in}^{2}$, and cellulitis.

Previous reports postulate that blood draws, injections, blood pressure readings, and trauma can cause infection and injury to the at-risk arm. 3,6,37-39 The theory is that patients with surgically removed lymph nodes have compromised lymphatic systems that cannot clear fluid resulting from an immune response, leading to build-up of lymphatic fluid in the arm and subsequent lymphedema. $^{37}$ One of the first papers to recommend precautionary behaviors was published in 1992 as a case report of a woman who developed swelling 30 years after treatment in response to a finger pinprick. ${ }^{40}$ Smith $^{37}$ advised avoidance of traumatic events to the atrisk arm after examining 10 patients with BCRL, four of whom reported blood draws as triggering their arm swelling. These studies are anecdotal and based on information from a small number of patients. Despite minimal data, the authors provided persistent recommendations to avoid blood draws, blood pressure readings, and injections in the at-risk arm to reduce the risk of lymphedema. $6,31,37,41$ The results of our prospective study provide evidence-based data that call these guidelines into question.

Clark et $\mathrm{al}^{41}$ evaluated 188 patients with breast cancer who underwent ALND and correlated skin punctures with risk of developing lymphedema. With a median follow-up of 3 years, $20.7 \%$ (39 of 188) of patients developed arm lymphedema, 9.6\% (18 of 188) of all patients had a skin puncture, and therefore $44 \%$ ( 8 of 18) of patients with skin puncture developed lymphedema during the follow-up period. ${ }^{41}$ This analysis performed a measurement for lymphedema at 6 months and 3 years after surgery 


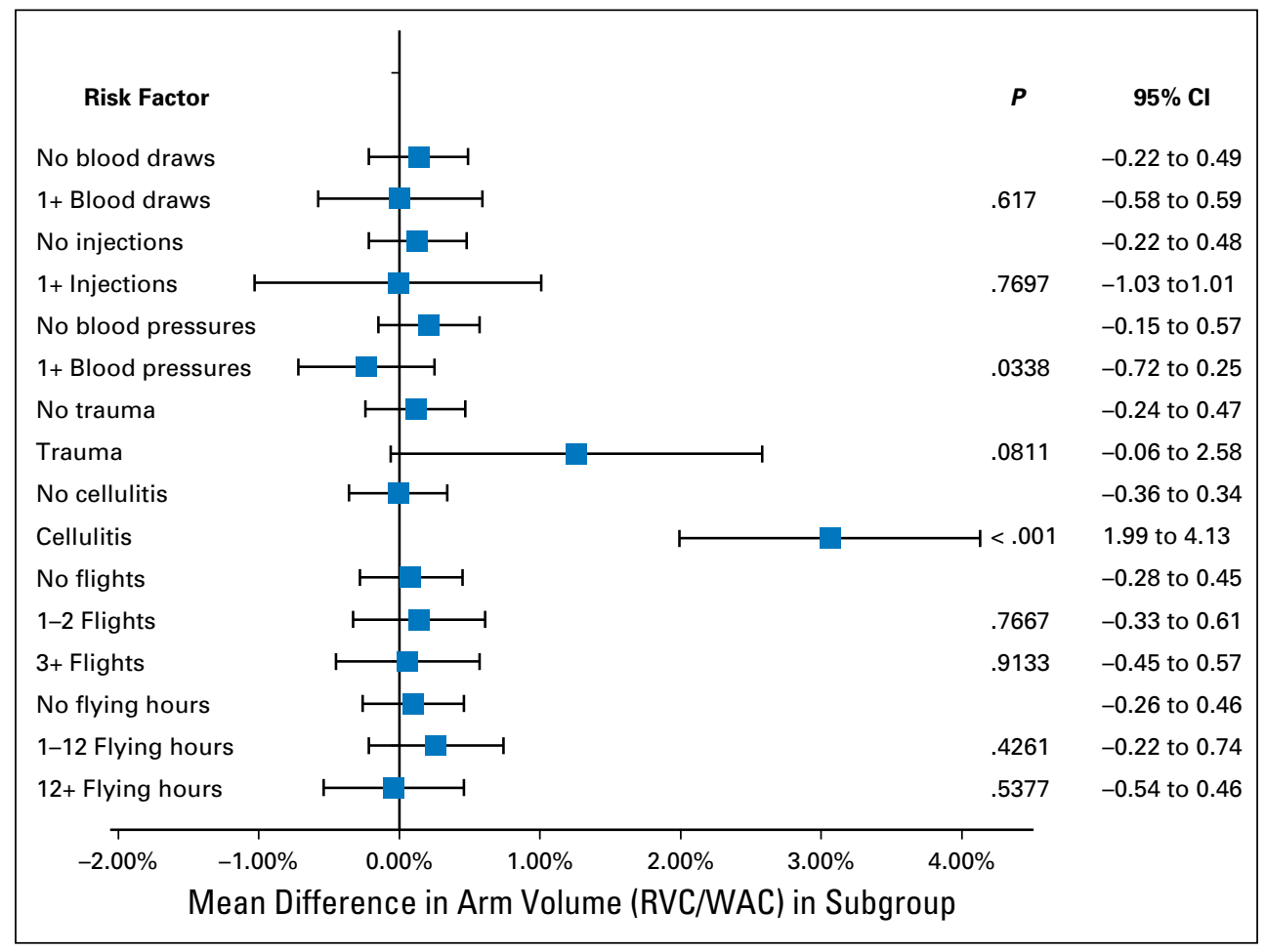

Fig 1. Univariate analysis of association between risk events and arm volume increases. RVC, relative volume change; WAC, weight-adjusted volume change.

and did not specify the timing of skin puncture; therefore, it did not take into account other events that could have contributed to lymphedema. ${ }^{42}$ In our subset analysis of 159 patients undergoing ALND, nonprecautionary risk behaviors and specifically skin puncture were not correlated with increased arm swelling. By performing arm measurements at regularly timed intervals for as long as 5 years and recording the number of nonprecautionary events since the previous measurement, we were able to reduce the recall bias and more specifically evaluate effects of nonprecautionary behavior on arm swelling.

\begin{tabular}{|c|c|c|c|}
\hline $\begin{array}{l}\text { Patient- or Treatment- } \\
\text { Related Risk Factor }\end{array}$ & $\begin{array}{l}\text { Mean RVCMAC } \\
\text { in Subgroup (\%) }\end{array}$ & $95 \% \mathrm{Cl}$ & $P$ \\
\hline \multicolumn{4}{|l|}{ Surgical characteristics } \\
\hline Lumpectomy & 0.04 & -0.42 to 0.51 & -* \\
\hline $\begin{array}{l}\text { Mastectomy } v \\
\text { lumpectomy }\end{array}$ & 0.26 & -0.28 to 0.79 & .5542 \\
\hline No nodal surgery & -0.22 & -1.22 to 0.78 & - \\
\hline SLNB $v$ none & -0.35 & -0.73 to 0.04 & .8113 \\
\hline ALND $v$ none & 1.89 & 1.22 to 2.55 & $<.001$ \\
\hline \multicolumn{4}{|l|}{ Radiation therapy } \\
\hline None & -0.00 & -0.43 to 0.43 & - \\
\hline $\begin{array}{l}\text { Breast/chest wall } \\
\text { irradiation } v \text { none }\end{array}$ & -0.20 & -0.65 to 0.25 & .42341 \\
\hline $\begin{array}{l}\text { Breast/chest wall + } \\
\text { RLNR } v \text { none }\end{array}$ & 1.29 & 0.65 to 1.88 & $<.001$ \\
\hline \multicolumn{4}{|l|}{$\mathrm{BMI}, \mathrm{Ib} / \mathrm{in}^{2}$} \\
\hline$<25$ & -0.43 & -0.98 to 0.11 & - \\
\hline$\geq 25$ & 0.57 & 0.10 to 1.03 & .0064 \\
\hline \multicolumn{4}{|c|}{$\begin{array}{l}\text { Abbreviations: ALND, axillary lymph node dissection; BMI, body mass index; } \\
\text { RLNR, regional lymph node irradiation; RVC, relative volume change; WAC, } \\
\text { weight-adjusted volume change. } \\
\text { *Indicates the specified variable or comparison was not analyzed. }\end{array}$} \\
\hline
\end{tabular}

In contrast, McLaughlin et $\mathrm{al}^{6}$ found no association in riskreducing behaviors of patients with and without lymphedema when evaluated using tape measured circumferential arm measurements. Circumferential tape measurement is limited because the measurements can be subject to both inter- and intrapersonal variation. ${ }^{43}$ Unlike tape measurements, measurements by the Perometer and use of the RVC and WAC formulas account for preexisting arm volume differences and detect small volume changes. In addition, obtaining reproducible, prospective arm measurements using the Perometer at the same time as collecting individual incidence of risk-related events could have biased our data to attribute small volume changes that may have not represented swelling detectable via circumferential tape measurement to risk events. Similarly, we found no association with nonprecautionary behavior and increase in arm volume.

The Physical Activity and Lymphedema (PAL) trial assessed the safety of progressive strength training in breast cancer survivors and investigated the association of 30 risk factors and arm swelling. ${ }^{44,45}$ The authors reported no significant association between ipsilateral blood draws, blood pressure readings, and air travel and incident arm swelling. ${ }^{44}$ The study included clinical evaluation of arm swelling using water displacement and patientreported risk-reducing behaviors at 3, 6, and 12 months after enrollment. ${ }^{44,45}$ Patients were given compression sleeves to wear during exercise and participated in a biweekly, year-long exercise program. The incidence of lymphedema as defined as interlimb difference increase of $\geq 5 \%$ was low, which may be due to wearing a compression sleeve or the exercise program. ${ }^{44,45}$ In addition, the incidence of nonprecautionary behaviors was also low, which may be due to the education about lymphedema provided to participants. Patients in our cohort do not routinely receive recommendations to avoid blood draws, injections, or blood pressure readings or to wear a 


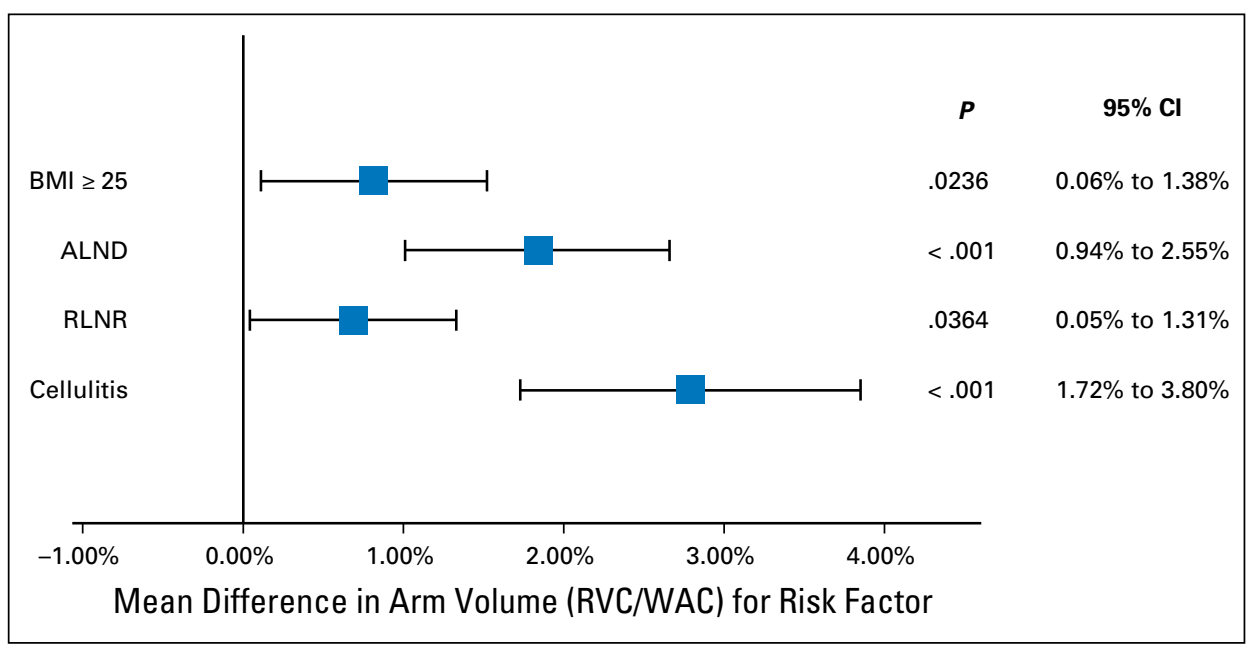

Fig 2. Multivariate analysis of risk factors associated with arm volume increases. ALND, axillary lymph node dissection; BMI, body mass index (in $\mathrm{lb} / \mathrm{in}^{2}$ ); RNLR, regional lymph node irradiation; RVC, relative volume change; WAC, weight-adjusted volume change. compressive sleeve while flying. However, our incidence of risk events was low, and we enhanced our patient cohort to include patients with both unilateral and bilateral breast surgery, increasing both the number of risk events and the overall incidence of lymphedema.

It has been reported that flying incites the development of lymphedema because of changes in cabin air pressure. ${ }^{6,46}$ Many clinicians recommend using risk-reducing compression sleeves when flying based on few, mostly retrospective, studies. ${ }^{47}$ In these studies it is unclear if the reported lymphedema was preexisting or influenced by other factors. Kilbreath et $\mathrm{al}^{48}$ evaluated changes in arm volume after short- and long-distance flights and found no change in arm volume as measured by bioimpedance. In our analysis, we prospectively collected information regarding air travel and quantified arm swelling with short intervals of follow-up. This design enabled the investigation of the immediate effects of flying on arm volume and minimized the risk of recall bias due to the shorter interval of follow up.

In our study, BMI $\geq 25 \mathrm{lb} / \mathrm{in}^{2}$ at diagnosis, ALND, RLNR, and cellulitis were significantly associated with arm swelling. High BMI, RLNR, and ALND are consistently cited in the literature as risk factors for arm swelling and lymphedema, and our data further support these claims. ${ }^{6,8,10,11,13-16,19,20,24,49,50}$ The increased risk for developing lymphedema after infection including cellulitis is also well documented in the literature,,$^{2,6,22,51}$ and our results support these findings. Interestingly in our cohort, episodes of cellulitis were not associated with a risk event that occurred before the cellulitis. This may be due to a lower incidence of risk events or to an overall lower risk of infection after risk events in a modern era of attention to sterility.

Limitations of the study include a relatively short median follow-up time of 24 months, low incidence of risk events, potential for recall bias, and lack of information about patients' receipt of physical therapy. As lymphedema has been shown to develop an average of 14.4 months after surgery, ${ }^{8}$ longer follow-up time would strengthen the study. Although efforts were made to ensure regular follow-up visits, future studies using repeat questionnaires and sensitivity analyses might elucidate the effects of recall bias. In addition, our analysis did not adjust for the number of positive lymph nodes because we have not found it to be significant in a previous analysis; however, this is an important area for future investigation. ${ }^{52}$ Finally, the study did not capture and therefore was not able to account for women who had physical therapy, which might have placed them at lower risk for developing swelling, even after risk events.

This study represents the largest cohort of patients with breast cancer prospectively screened for lymphedema using preoperative arm measurements to determine the impact of risk-reducing practices on arm swelling. We evaluated the association between risk events and changes in arm volume and found no significant associations between air travel, blood draws, injections, and blood pressure readings in the at-risk arm with arm volume increase. Patients who have a BMI $\geq 25 \mathrm{lb} / \mathrm{in}^{2}$, underwent ALND or RLNR, and have had an episode of cellulitis should be more closely monitored for changes in arm volume because of the significant association with arm volume increases. The recommendations set forth in the studies discussed still persist today and unfortunately are supported with few evidence-based data. Although we cannot affirmatively state that risk-reduction practices have no effect on arm swelling, we hope to generate evidence that brings reasonable doubt to burdensome guidelines and encourage further investigation into nonprecautionary behaviors and the risk of lymphedema.

\section{AUTHORS' DISCLOSURES OF POTENTIAL CONFLICTS} OF INTEREST

Disclosures provided by the authors are available with this article at www.jco.org.

\section{AUTHOR CONTRIBUTIONS}

Conception and design: Chantal M. Ferguson, Meyha N. Swaroop, Melissa N. Skolny, Cynthia L. Miller, Lauren S. Jammallo, Cheryl Brunelle, Jean A. O’Toole, Michelle C. Specht, Alphonse G. Taghian

Collection and assembly of data: Chantal M. Ferguson, Meyha N. Swaroop, Melissa N. Skolny, Cynthia L. Miller, Lauren S. Jammallo, Jean A. O’Toole, Laura Salama, Alphonse G. Taghian

Data analysis and interpretation: Chantal M. Ferguson, Meyha N. Swaroop, Nora Horick, Melissa N. Skolny, Cynthia L. Miller, Lauren S. Jammallo, Cheryl Brunelle, Michelle C. Specht, Alphonse G. Taghian Manuscript writing: All authors

Final approval of manuscript: All authors 


\section{REFERENCES}

1. American Cancer Society: Lymphedema: What every woman with breast cancer should know-For women at risk for lymphedema. http://www.cancer. org/acs/groups/cid/documents/webcontent/002876pdf.pdf

2. Indelicato DJ, Grobmyer SR, Newlin $\mathrm{H}$, et al: Delayed breast cellulitis: An evolving complication of breast conservation. Int J Radiat Oncol Biol Phys 66: 1339-1346, 2006

3. Loudon L, Petrek J: Lymphedema in women treated for breast cancer. Cancer Pract 8:65-71, 2000

4. National Lymphedema Network: Supplement to NLN position breast cancer screening: Screening and early detection of breast cancer-related lymphedema-The imperative. http://www.lymphnet. org/pdfDocs/PP_Lymphedema_BC_Supplement.pdf

5. National Lymphedema Network: Position statement of the National Lymphedema Network: Lymphedema risk reduction practices. http://www. lymphnet.org/pdfDocs/nlnriskreduction.pdf

6. McLaughlin SA, Bagaria S, Gibson $T$, et al: Trends in risk reduction practices for the prevention of lymphedema in the first 12 months after breast cancer surgery. J Am Coll Surg 216:380-389, 2013; quiz 511-513

7. DiSipio $T$, Rye $S$, Newman B, et al: Incidence of unilateral arm lymphoedema after breast cancer: A systematic review and meta-analysis. Lancet Oncol 14:500-515, 2013

8. Specht $M C$, Miller $C L$, Russell $T A$, et al: Defining a threshold for intervention in breast cancerrelated lymphedema: What level of arm volume increase predicts progression? Breast Cancer Res Treat 140:485-494, 2013

9. Shih $Y C, X u Y$, Cormier JN, et al: Incidence, treatment costs, and complications of lymphedema after breast cancer among women of working age: $\mathrm{A}$ 2-year follow-up study. J Clin Oncol 27:2007-2014, 2009

10. Mansel RE, Fallowfield L, Kissin M, et al: Randomized multicenter trial of sentinel node biopsy versus standard axillary treatment in operable breast cancer: The ALMANAC Trial. J Natl Cancer Inst 98: 599-609, 2006

11. Norman SA, Localio AR, Kallan MJ, et al: Risk factors for lymphedema after breast cancer treatment. Cancer Epidemiol Biomarkers Prev 19: 2734-2746, 2010

12. Yang EJ, Park WB, Seo KS, et al: Longitudinal change of treatment-related upper limb dysfunction and its impact on late dysfunction in breast cancer survivors: A prospective cohort study. J Surg Oncol 101:84-91, 2010

13. Lucci A, McCall LM, Beitsch PD, et al: American College of Surgeons Oncology Group: Surgical complications associated with sentinel lymph node dissection (SLND) plus axillary lymph node dissection compared with SLND alone in the American College of Surgeons Oncology Group Trial Z0011. J Clin Oncol 25:3657-3663, 2007

14. Park JH, Lee WH, Chung HS: Incidence and risk factors of breast cancer lymphoedema. J Clin Nurs 17:1450-1459, 2008

15. Tsai RJ, Dennis LK, Lynch CF, et al: The risk of developing arm lymphedema among breast cancer survivors: A meta-analysis of treatment factors. Ann Surg Oncol 16:1959-1972, 2009
16. Warren $L E$, Miller $C L$, Horick $N$, et al: The impact of radiation therapy on the risk of lymphedema after treatment for breast cancer: A prospective cohort study. Int J Radiat Oncol Biol Phys 88:565-571, 2014

17. Coriddi M, Khansa I, Stephens J, et al: Analysis of factors contributing to severity of breast cancerrelated lymphedema. Ann Plast Surg 74:22-25, 2015

18. Tiwari $P$, Coriddi $M$, Lamp S: Lymphedema strategies for investigation and treatment: A review. Plast Surg Nurs 32:173-177, 2012; quiz 178-179

19. Hayes SB, Freedman GM, Li T, et al: Does axillary boost increase lymphedema compared with supraclavicular radiation alone after breast conservation? Int J Radiat Oncol Biol Phys 72:1449-1455, 2008

20. Jammallo LS, Miller $C L$, Singer $M$, et al: Impact of body mass index and weight fluctuation on lymphedema risk in patients treated for breast cancer. Breast Cancer Res Treat 142:59-67, 2013

21. Ahmed RL, Schmitz KH, Prizment AE, Folsom AR: Risk factors for lymphedema in breast cancer survivors, the lowa Women's Health Study. Breast Cancer Res Treat 130:981-991, 2011

22. McLaughlin SA, Wright MJ, Morris KT, et al: Prevalence of lymphedema in women with breast cancer 5 years after sentinel lymph node biopsy or axillary dissection: Objective measurements. J Clin Oncol 26:5213-5219, 2008

23. Wilke LG, McCall LM, Posther KE, et al: Surgical complications associated with sentinel lymph node biopsy: Results from a prospective international cooperative group trial. Ann Surg Oncol 13:491-500, 2006

24. Soran A, Wu WC, Dirican A, et al: Estimating the probability of lymphedema after breast cancer surgery. Am J Clin Oncol 34:506-510, 2011

25. Swenson KK, Nissen MJ, et al: Case-control study to evaluate predictors of lymphedema after breast cancer surgery. Oncol Nurs Forum 36: 185-193, 2009

26. Nesvold IL, Dahl AA, Løkkevik E, et al: Arm and shoulder morbidity in breast cancer patients after breast-conserving therapy versus mastectomy. Acta Oncol 47:835-842, 2008

27. Hayes SC, Janda M, Cornish B, et al: Lymphedema after breast cancer: Incidence, risk factors, and effect on upper body function. J Clin Oncol 26: 3536-3542, 2008

28. Paskett ED, Naughton MJ, McCoy TP, et al: The epidemiology of arm and hand swelling in premenopausal breast cancer survivors. Cancer Epidemiol Biomarkers Prev 16:775-782, 2007

29. Crosby MA, Card A, Liu J, et al: Immediate breast reconstruction and lymphedema incidence. Plast Reconstr Surg 129:789e-795e, 2012

30. Ozaslan C, Kuru B: Lymphedema after treatment of breast cancer. Am J Surg 187:69-72, 2004

31. Cole T: Risks and benefits of needle use in patients after axillary node surgery. Br J Nurs 15: 969974, 976-979, 2006

32. Ancukiewicz M, Miller CL, Skolny MN, et al: Comparison of relative versus absolute arm size change as criteria for quantifying breast cancerrelated lymphedema: The flaws in current studies and need for universal methodology. Breast Cancer Res Treat 135:145-152, 2012

33. Ancukiewicz M, Russell TA, Otoole J, et al: Standardized method for quantification of developing lymphedema in patients treated for breast cancer. Int J Radiat Oncol Biol Phys 79:1436-1443, 2011
34. Miller CL, Specht MC, Horick N, et al: A novel, validated method to quantify breast cancer-related lymphedema (BCRL) following bilateral breast surgery. Lymphology 46:64-74, 2013

35. O'Toole J, Russell T, Singer M, et al: A general hospital's multi-disciplinary approach to BCRL. J Lymphoedema 5:81-85, 2010

36. Armer JM, Heckathorn PW: Post-breast cancer lymphedema in aging women: Self-management and implications for nursing. J Gerontol Nurs 31: 29-39, 2005

37. Smith J: The practice of venepuncture in lymphoedema. Eur J Cancer Care (Engl) 7:97-98, 1998

38. Davis S: Lymphedema following breast cancer treatment. Radiol Technol 70:42-56, 1998; quiz 57-60

39. Drury AN, Jones NW: Observations upon the rate at which edema forms when the veins of the human limb are congested. Heart 2:580-581, 1927

40. Brennan MJ, Weitz J: Lymphedema 30 years after radical mastectomy. Am J Phys Med Rehabil 71:12-14, 1992

41. Clark B, Sitzia J, Harlow W: Incidence and risk of arm oedema following treatment for breast cancer: A three-year follow-up study. QJM 98:343-348, 2005

42. Cemal $Y$, Pusic A, Mehrara BJ: Preventative measures for lymphedema: Separating fact from fiction. J Am Coll Surg 213:543-551, 2011

43. Deltombe T, Jamart J, Recloux S, et al: Reliability and limits of agreement of circumferential, water displacement, and optoelectronic volumetry in the measurement of upper limb lymphedema. Lymphology 40:26-34, 2007

44. Showalter SL, Brown JC, Cheville AL, et al: Lifestyle risk factors associated with arm swelling among women with breast cancer. Ann Surg Oncol 20:842-849, 2013

45. Schmitz KH, Troxel AB, Cheville A, et al: Physical Activity and Lymphedema (the PAL trial): Assessing the safety of progressive strength training in breast cancer survivors. Contemp Clin Trials 30: 233-245, 2009

46. Casley-Smith JR, Casley-Smith JR: Lymphedema initiated by aircraft flights. Aviat Space Environ Med 67:52-56, 1996

47. Graham PH: Compression prophylaxis may increase the potential for flight-associated lymphoedema after breast cancer treatment. Breast 11: 66-71, 2002

48. Kilbreath SL, Ward LC, Lane K, et al: Effect of air travel on lymphedema risk in women with history of breast cancer. Breast Cancer Res Treat 120: 649-654, 2010

49. Shahpar H, Atieh A, Maryam A, et al: Risk factors of lymph edema in breast cancer patients. Int J Breast Cancer 2013:641818, 2013

50. Graham $P$, Jagavkar $R$, Browne $L$, et al: Supraclavicular radiotherapy must be limited laterally by the coracoid to avoid significant adjuvant breast nodal radiotherapy lymphoedema risk. Australas Radiol 50:578-582, 2006

51. Mak SS, Yeo W, Lee YM, et al: Predictors of lymphedema in patients with breast cancer undergoing axillary lymph node dissection in Hong Kong. Nurs Res 57:416-425, 2008

52. Miller $\mathrm{CL}$, Skolny M, Ferguson $\mathrm{C}$, et al: Does number of sentinel lymph nodes removed impact the risk of breast cancer- related lymphedema (BCRL)? The National Lymphedema Network Conference, 11th International Conference, Washington DC , September 3-7, 2014 


\section{GLOSSARY TERM}

sentinel lymph node: the lymph node that is anatomically located such that it is the first site of lymph drainage from the location of the primary tumor. It is suspected and assumed that if a malignancy is going to disseminate via the lymphatic system, metastases will first be evident in the sentinel lymph node. In this manner, this lymph node is said to stand guard or sentinel over the metastatic state of the tumor. For many cancers, the sentinel lymph node is biopsied as part of the staging process and presence of macroor micrometastases in the sentinel lymph node is a negative prognostic factor. 


\section{AUTHORS' DISCLOSURES OF POTENTIAL CONFLICTS OF INTEREST}

Impact of Ipsilateral Blood Draws, Injections, Blood Pressure Measurements, and Air Travel on the Risk of Lymphedema for Patients Treated for Breast Cancer

The following represents disclosure information provided by authors of this manuscript. All relationships are considered compensated. Relationships are self-held unless noted. I = Immediate Family Member, Inst = My Institution. Relationships may not relate to the subject matter of this manuscript. For more information about ASCO's conflict of interest policy, please refer to www.asco.org/rwc or jco.ascopubs.org/site/ifc.

\section{Chantal M. Ferguson}

No relationship to disclose

Meyha N. Swaroop

No relationship to disclose

Nora Horick

No relationship to disclose

Melissa N. Skolny

No relationship to disclose

Cynthia L. Miller

No relationship to disclose

Lauren S. Jammallo

No relationship to disclose
Cheryl Brunelle

No relationship to disclose

Jean A. O'Toole

No relationship to disclose

Laura Salama

No relationship to disclose

Michelle C. Specht

No relationship to disclose

Alphonse G. Taghian

Research Funding: ImpediMed L-Dex 